\title{
Early Brain Damage and the Development of Motor Behavior in Children: Clues for Therapeutic Intervention?
}

\author{
Mijna Hadders-Algra \\ Department of Neurology, University of Groningen, Groningen, The Netherlands ${ }^{\dagger}$
}

\begin{abstract}
The Neuronal Group Selection Theory (NGST) could offer new insights into the mechanisms directing motor disorders, such as cerebral palsy and developmental coordination disorder. According to NGST, normal motor development is characterized by two phases of variability. Variation is not at random but determined by criteria set by genetic information. Development starts with the phase of primary variability, during which variation in motor behavior is not geared to external conditions. At function-specific ages secondary variability starts, during which motor performance can be adapted to specific situations. In both forms, of variability, selection on the basis of afferent information plays a significant role. From the NGST point of view, children with pre- or perinatally acquired brain damage, such as children with cerebral palsy and part of the children with developmental coordination disorder, suffer from stereotyped motor behavior, produced by a limited repertoire or primary (sub)cortical neuronal networks. These children also have problems in selecting the most efficient neuronal activity, due to deficits in the processing of sensory information. Therefore, NGST suggests
\end{abstract}

\footnotetext{
${ }^{\dagger}$ Correspondence to:

Developmental Neurology

CMC-IV, $3^{\text {rd }}$ floor, Hanzeplein 1

$9713 \mathrm{KZ}$ Groningen, the Netherlands

tel: +31503614247 ; fax: +31503636905

e-mail: m.hadders-algra@med.rug.nl
}

that intervention in these children at early age should aim at an enlargement of the primary neuronal networks. With increasing age, the emphasis of intervention could shift to the provision of ample opportunities for active practice, which might form a compensation for the impaired selection.

\section{KEYWORDS}

Neuronal Group Selection Theory, variability, selection, developmental coordination disorder, cerebral palsy

\section{INTRODUCTION}

During the last century, knowledge on motor control rapidly increased, an expansion of knowledge which was associated with changes in the concepts on the organization of motor behavior. Motor behavior is no longer explained in terms of reflex mechanisms (Sherrington, 1906; Magnus \& De Kleijn, 1912). On the contrary, motility is nowadays regarded as the net result of the activity of complex spinal or brainstem machineries, which are subtly modulated by segmental afferent information and ingeniously controlled by supraspinal networks (Schomburg, 1990; Grillner et al., 1995). For instance, it is assumed that motor control of rhythmical move-ments like locomotion, respiration, sucking, and mastication is based on so-called Central Pattern Generators (CPGs). CPGs 
are neuronal networks which can generate complex basic activation patterns of the muscles without any sensory signals. Yet, sensory information of the movement is important in adapting the movement to the environment.

The activity of the networks, which are usually thought to be located in the spinal cord or brain stem, is controlled from supraspinal areas via descending motor pathways (Grillner et al., 1995). The supraspinal activity itself is also organized in networks, large-scale ones, in which cortical areas are functionally connected through direct recursive interaction or through intermediary cortical or subcortical (striatal, cerebellar) structures (Bressler, 1995; Hikosaka et al., 1999, Liu et al., 1999). The supraspinal motor networks are the circuitries which expanded in particular during phylogeny and which determine, to a large extent, human motor ontogeny.

Research in the area of human motor development is characterized by an ongoing debate on the role of endogenous and exogenous factors. In the present paper, it is argued that this 'nature-nurture' controversy could be eliminated by the application of a new perspective, i.e., the perspective of the Neuronal Group Selection Theory (NGST). The paper presents an outline of NGST and describes the significance of NGST for understanding normal and abnormal motor development. The paper concludes with suggestions for therapeutical interventions in children who acquired a brain lesion at early age-suggestions that are based on the function-specific plasticity windows indicated by NGST.

\section{THEORIES ON MOTOR DEVELOPMENT}

\section{Neural-Maturationst/Dynamic System Theories}

For many years, normal motor development has been interpreted within the framework of the
Neural-Maturationist Theories. These theories suggest that motor development is based on a gradual unfolding of predetermined patterns in the central nervous system and an increasing cortical control over lower reflexes (McGraw, 1943; Gesell \& Amatruda, 1947; Peiper, 1963). According to the Neural-Maturationist Theories, motor development follows distinct rules, such as the cephalo-caudal and central-to-distal sequences of development. The theories leave only little room for developmental modifications by means of environmental factors and experience ${ }^{1}$.

A more recently developed theory, the Dynamic Systems Theory, considers such a virtual neglect of a contribution of external factors to motor development as incompatible with reality (Thelen, 1995). According to the Dynamic Systems Theory, motor development is regarded as a dynamic system, i.e., a complex system which changes over time due to the interaction of multiple components. The components consist of intrinsic factors, such as muscle strength, body weight, postural support, the infant's mood and brain development; and extrinsic factors, such as the environmental condition and specific task requirements. The Dynamic Systems Theory postulates that motor behavior spontaneously adopts specific, temporarily attractive states of organization. Behavior changes and develops in a non-linear way, i.e., by means of transitions, due to changes of the characteristics of the intrinsic or extrinsic component parts (Thelen, 1985, 1995; Thelen et al., 1993; Ulrich, 1997). In other words, the Dynamic Systems Theory and the Neural-Maturationist Theories differ, especially in their view on the role of the nervous system in motor development. The Neural-Maturationist Theories consider the endogenously driven

\footnotetext{
${ }^{1}$ Among the Neural-Maturationists, McGraw has an atypical position. Even though she considered endogenous maturational processes the main driving forces of development, she acknowledged that experience during particular time-windows could modify motor development (McGraw, 1935, 1943).
} 
maturational state of the nervous system the main constraint for developmental progress, whereas in the Dynamic Systems Theory, the make-up of the neural substrate plays a subordinate role only.

\section{Neuronal Group Selection Theory}

Recently, Gerald M. Edelman developed a new theoretical concept on neural development: the Neuronal Group Selection Theory (NGST; Edelman, 1989, 1993; Sporns \& Edelman, 1993). This theory could offer the golden mean between the Neuro-Maturationist and Dynamic Systems theories and might facilitate the understanding of the effects of brain damage at early age (HaddersAlgra, 2000a,b). According to NGST, the brainor more specifically, the ensemble of cortical and subcortical systems-is dynamically organized into variable networks, the structure and function of which are selected by development and behavior. The units of selection are collections of hundreds to thousands of strongly interconnected neurons, called neuronal groups. These units act as functional units dealing, for instance, with a specific type of motor behavior or information from a specific sensory modality. NGST states that development starts with primary neuronal repertoires, with each repertoire consisting of multiple neuronal groups (Fig. 1). The cells and the crudely specified connectivity of the primary repertoires are determined by evolution. In other words, genetic information plays a substantial role in the primary determination of brain development. For instance, it is thought that the area-specific characteristics of the neo-cortex is partially based on properties laid down at the time of neurogenesis (O'Leary, 1989).

Another indication that genetic information contributes significantly to brain development is the fact that at least $50 \%$ of tissue-specific human genes are expressed in the brain (Evans, 1998). A primary genetic determination does, however, not preclude variation as primary determination is only the starting point for epigenetic cascades allowing for interaction with the environment. The latter results in a dynamic regulation of cell division, adhesion, migration, death, and neurite extension and retraction (Changeux \& Danchin 1976; Rakic, 1988; O'Leary, 1989; Changeux, 1997). In the initial assembly of the brain, synaptic activity most probably plays a role. Still, a permanent and complete loss of synaptic transmission does not prevent a normal assembly, including a normal formation of layered structures, fiber pathways, and morphologically defined synapses. Synaptic activity is, however, needed for the maintenance of neuronal structures and connections (Verhage et al., 2000).

When the primary neuronal groups have been formed, development proceeds with selection on the basis of afferent information produced by behavior and experience (Fig. 1). The selection process is thought to be mediated by changes in synaptic strength of intra- and inter-group connections, in which the topology of the cells (Nelson et al., 1993) and the presence or absence of coincident electrical activity in pre- and postsynaptic neurons plays a role (Hebb, 1949; Changeux \& Danchin, 1976). When the selection has just been accomplished, behavioral variation is slightly reduced. Soon, however, abundant variation returns because the organism and its populations of neurons is constantly exposed to a multitude of experiences. The experiential afferent information induces modifications in the strength of the synaptic connections within and between the neuronal groups, resulting in the variable secondary repertoire (Fig. 1). The changed and changing connectivity within the secondary repertoire allows for a situation- specific selection of neuronal groups. Thus, the secondary neuronal repertoires and their associated selection mechanisms form the basis of mature variable behavior, which can be adapted to environmental constraints (Edelman \& Tononi, 2000). 


\section{primary neuronal repertoire}
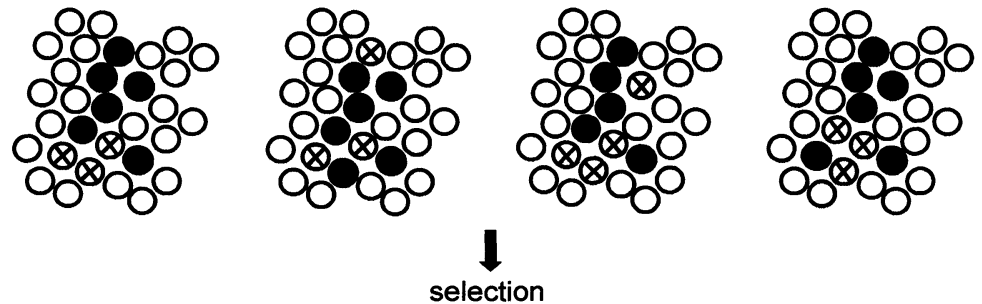

selection

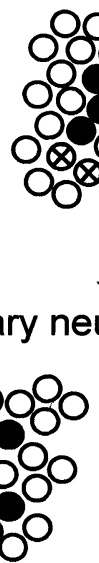

secondary neuronal repertoire
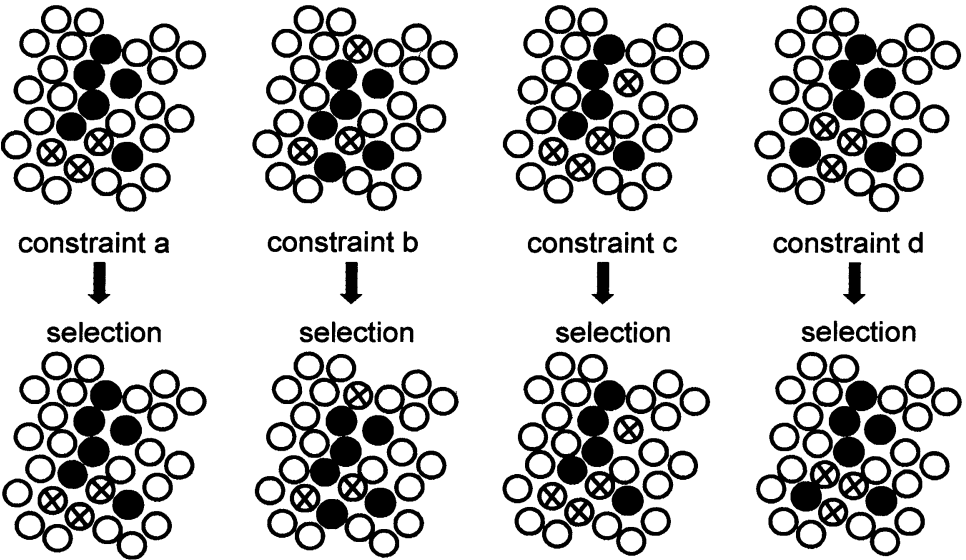

Fig. 1: Schematic representation of Edelman's Neuronal Group Selection Theory. Each circle represents a cluster of supraspinally localized neurons, i.e., the neurons are localized in cortical, cortico-striato-thalamo-cortical, or cortico-cerebellar-cortical networks. At the upper row, neural activity is depicted at early age at four closely spaced points in time. The filled circles $(\mathbf{O}=$ and $\otimes)$ denote neurons genetically determined to control a specific type of motor behavior, that is, they reflect a primary neuronal repertoire. For instance, the filled circles could denote neurons controlling the motoneurones of the muscles on the ventral side of the body which are genetically determined to be in charge of postural control during a backward sway of the body (direction-specificity). The open circles (O)represent neurons genetically linked to other types of behavior, i.e., other primary neuronal repertoires. At the four different points in time, the filled primary neural repertoire is activated in four different configurations, i.e., four different neuronal groups - denoted by the different grades of filling of the clusters $(\Theta=$ active; $\otimes=$ inactive) This, in turn, gives rise to primary variability in behavior. Development proceeds (7) with selection of the neuronal group, which produces the most effective behavior applicable in a wide variation of conditions. For instance, returning to the example of postural control, during the development of postural adjustments, selection occurs of the adjustment in which all direction specific muscles are activated (Hadders-Algra et al. 1996a,b; Fig. $2)$. Next $(\boldsymbol{y})$, with increasing age variation returns, giving rise to the secondary neural repertoire. The variation of the secondary neural repertoire can best be observed in conditions lacking tight constraints. In the absence of specific constraints, the nervous systems shows that it has access to many motor roads leading to Rome. This means that easy, unconstrained conditions allow for variation of motor behavior, also in adulthood. Yet, in conditions with constraints (lower part of the figure), a specific solution produced by the activity of a specific neuronal group is selected, the solution being geared to the specifics of the situation. 


\section{NGST AND NORMAL MOTOR DEVELOPMENT}

Translation of the concept of NGST to motor development implies that motor development is characterized by two phases of variation: primary and secondary variability (Hadders-Algra, 2000a).

\section{Primary variability}

Motor development starts during early fetal life with the phase of primary variability, a phase which continues during infancy. Detailed studies on the motor behavior of fetuses and newborn infants have shown that motility at early age is characterized by profuse variation, such as variation in movement trajectories and variation in temporal and quantitative aspects of motility (Minkowski, 1938; De Vries et al., 1982; Forssberg, 1985; Vles et al., 1989; Hadders-Algra et al., 1992; Konishi et al., 1994). These variations in motor activity are not neatly tuned to environmental conditions, but the variations themselves constitute a fundamental developmental phenomenon. It is conceivable that the abundant variation in motility is brought about by activity of the epigenetically determined, but rather grossly specified, supraspinal primary neural repertoires. The system of primary repertoires presumably explores by means of self-generated activity, and consequently also by means of self-generated afferent information, all motor possibilities available within the neurobiological and anthropometric constraints set by evolution.

The properties of primary variability are well illustrated by the general movements (GMs). GMs are the most frequently used movement pattern of the human fetus and newborn infant. They consist of a series of gross movements of variable speed and amplitude, which involve all parts of the body but lack a distinctive sequencing of the participating body parts (Prechtl \& Nolte, 1984; Prechtl, 1990). In other words, normal GMs are very variable and consist of an endless exploration of all potential movement properties, such as movement velocities, amplitudes, and forces; and the numerous possible combinations of actions around all participating joints. Likewise, the muscle coordination patterns of normal GMs are typified by variation - variation in which muscles participate and variation in the timing and the quantity of muscle activation (Hadders-Algra et al., 1992, 1997). Presumably, the rich variation and the complexity of human GMs reflect the explorative activity of a widely distributed (sub)cortical network - the primary neuronal repertoire-on the extensive CPG-networks of the GMs localized in the spinal cord and brainstem (Hadders-Algra, 2000a). GMs are present till about 4 months of post-term age. From that age onwards, they are gradually replaced by goal-directed movements. In terms of neural networks, the gradual change from general movement activity into goal-directed behavior could mean that the widely distributed (sub)cortical networks controlling GM-activity are flexibly rearranged by means of changed synaptic connectivity into multiple smaller networks (cf. Simmers et al., 1995). In other words, the large (sub)cortical GM-network is cut into various smaller networks. These smaller (sub)cortical networks form the primary neuronal repertoires for the control of specific motor behaviors, such as goal-directed motility of the arms and the legs, and postural control. Due to the dissolution of the primary neuronal network of GMs, the development of GMs does not include a transition from a primary neuronal repertoire into a secondary repertoire. This underscores the unique position of GMs in human motor development and supports the notion that the (sub)cortical networks involved in the control of GM-activity form the neural building blocks for later motor skills.

All other forms of motor behavior manifest both phases of variability. They start with the phase of primary variability, during which motor activity is variable and not strictly tuned to 


\section{TABLE 1}

Timing of selection in the phase of primary variability

\begin{tabular}{|c|c|c|}
\hline Movement pattern & Period during which selection occurs & Based on \\
\hline Well-coordinated sucking pattern & Before term age & Hadders-Algra \& Dirks (2000) \\
\hline $\begin{array}{l}\text { Relatively straightly forward directed } \\
\text { arm movement during reaching }\end{array}$ & Second half year after birth & $\begin{array}{l}\text { Thelen et al. (1993), Konczak et al. } \\
\text { (1995) }\end{array}$ \\
\hline $\begin{array}{l}\text { Efficient, multi-purpose postural } \\
\text { adjustments ('complete' patterns) }\end{array}$ & $6-10$ months & $\begin{array}{l}\text { Hadders-Algra et al. (1996a), Van der } \\
\text { Fits et al. (1999c) }\end{array}$ \\
\hline Diagonal gait during crawling & $6-10$ months & Adolph et al. (1998) \\
\hline Heel-strike during locomotion & $1-1 \frac{1}{2}$ years & $\begin{array}{l}\text { Burnett \& Johnson (1971), Cioni et } \\
\text { al. (1993) }\end{array}$ \\
\hline
\end{tabular}

environmental conditions. Primary variability occurs during fetal life and infancy, when brain development is characterized by an overproduction and subsequent pruning of neural elements (e.g., Huttenlocher et al., 1982, Rakic et al., 1986). The rich variation in motor behavior has been documented for the first phases of reaching and grasping behavior (Von Hofsten, 1991; Thelen et al., 1993; Fallang et al., 2000), crawling (Largo et al., 1985; Adolph et al., 1998), locomotor motility (Statham \& Murray, 1971; Forssberg, 1985), and postural control (Hirschfeld \& Forssberg, 1994, Hadders- Algra et al., 1996a; Van der Fits et al., 1999b).

The neural systems dedicated to a specific function explore during the phase of primary variability all motor possibilities available for that specific function. The exploration utilizes ubiquitous information and results in so-called 'experienceexpectant' information storage (Greenough et al., 1987). The trial and error exploration is associated with a continuous processing of self-generated afferent information, on the basis of which the most efficient movement patterns are selected. The time of occurrence of the phase of selection and the duration of the transition from the phase of primary to secondary variability is functionspecific (Table 1). After the transient phase of selection and reduced variation, the phase of secondary or adaptive variability starts (Touwen, 1993; Hadders-Algra et al., 1998).

\section{Transition from primary to secondary variability}

The transition from primary into secondary variability can be illustrated with data on the development of postural adjustments. We performed a series of studies on postural adjustments in children who sat on a movable platform. We found that the early phases of the development of postural adjustments are characterized by extensive variation, be it within the limits set by the primary neuronal repertoire, i.e., the epigenetically determined boundaries of direction specificity (Hadders-Algra et al., 1996a). Direction specificity denotes the mechanism to primarily activate the muscles on the dorsal side of the body when the body sways forward, and to primarily activate the ventral 
muscles when the body is swaying in the opposite direction (Forssberg \& Hirschfeld, 1994). Indeed, already before infants can sit independently, i.e., at 5 to 6 months, the postural activity of neck and trunk muscles is direction specific. At this age, the repertoire of direction-specific postural adjustments to large perturbations of equilibrium is variable and consists of adjustments in which one, or two, or more than two postural muscles are activated in any conceivable combination. The selection of the most efficient postural adjustment, in which all direction-specific neck, trunk, and proximal leg muscles are activated, occurs during the third postnatal trimester and is guided by information on the stability of the head in space (Hadders-Algra et al., 1996a; Fig. 2). The selection can be accelerated substantially by daily balance training, a finding which underscores the significance of active experience in the selection process (Hadders-Algra et al., 1996b).

The selection induces a transient phase with reduced variation. In the development of postural adjustments, the phase of reduced variation lasts relatively long, i.e., from 9 months until about $2 \frac{1}{2}$ years of age. The protracted presence of decreased variability in the development of postural control is presumably related to the difficulty of the task of balancing the body during the first phases of standing and walking (Hadders-Algra et al., 1998). In the development of the majority of motor functions, the phase of reduced variation is shortso short that the phase of primary variability imperceptibly passes into the phase of secondary variability (Adolph et al., 1998).

\section{Secondary variability}

When the secondary variability is formed, the brain is characterized by extensive synapse rearrangement, the net result of synapse formation and synapse elimination (Purves, 1994). In addition, processing times become increasingly shorter, which in part can be attributed to ongoing myelination (Jernigan et al., 1991; Müller et al., 1994). During this phase, a variable movement repertoire is created with an efficient motor solution for each specific situation. The development of situation-specific motor strategies is guided by active trial-and-error learning, based on experiences which are unique to the individual (Greenough et al., 1987: 'experiencedependent' information storage). Between the ages of 2 and 3 years, the secondary motor variation starts to bloom, but it lasts until adolescence before the motor repertoire is mature. In the mature situation, subjects can adapt movements exactly and efficiently to task specific conditions or, in the absence of tight constraints, generate a repertoire of motor solutions for a single motor task (e.g., Diener et al., 1983; Van der Fits et al., 1998; Forssberg et al., 1999b).

\section{NGST AND MOTOR DEVELOPMENT AFTER BRAIN LESION AT EARLY AGE}

\section{Motor disorders after brain lesion at early age}

The outcome after brain damage acquired in the pre-, peri-, or neonatal period is heterogeneous. Some children recover completely, whereas others suffer from severe handicapping conditions (Costello et al., 1988; Ford et al., 1989). The developmental sequelae are to some extent related to the size and the site of the lesion and the timing of the insult. The size of the lesion predicts outcome best. Lesions involving multiple cortical areas, especially those including subcortical damage, almost always result in clearly handicapping conditions, such as moderate to severe forms of $\mathrm{CP}$, whereas restricted focal lesions have motor outcomes which vary between a normal condition, clumsiness, and mild to moderate forms of CP (Fawer et al., 1987; Fazzi et al., 1994; Hadders-Algra et al., 1999a; Forssberg et al., 


\section{5-6 MONTHS}
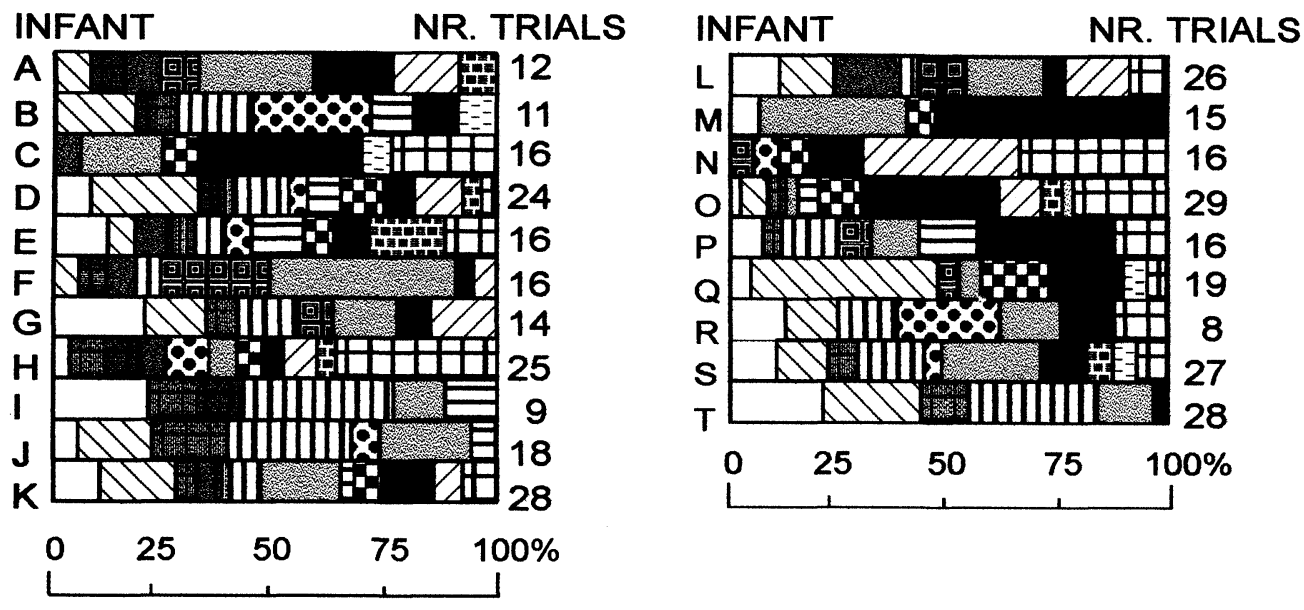

\section{9-10 MONTHS}
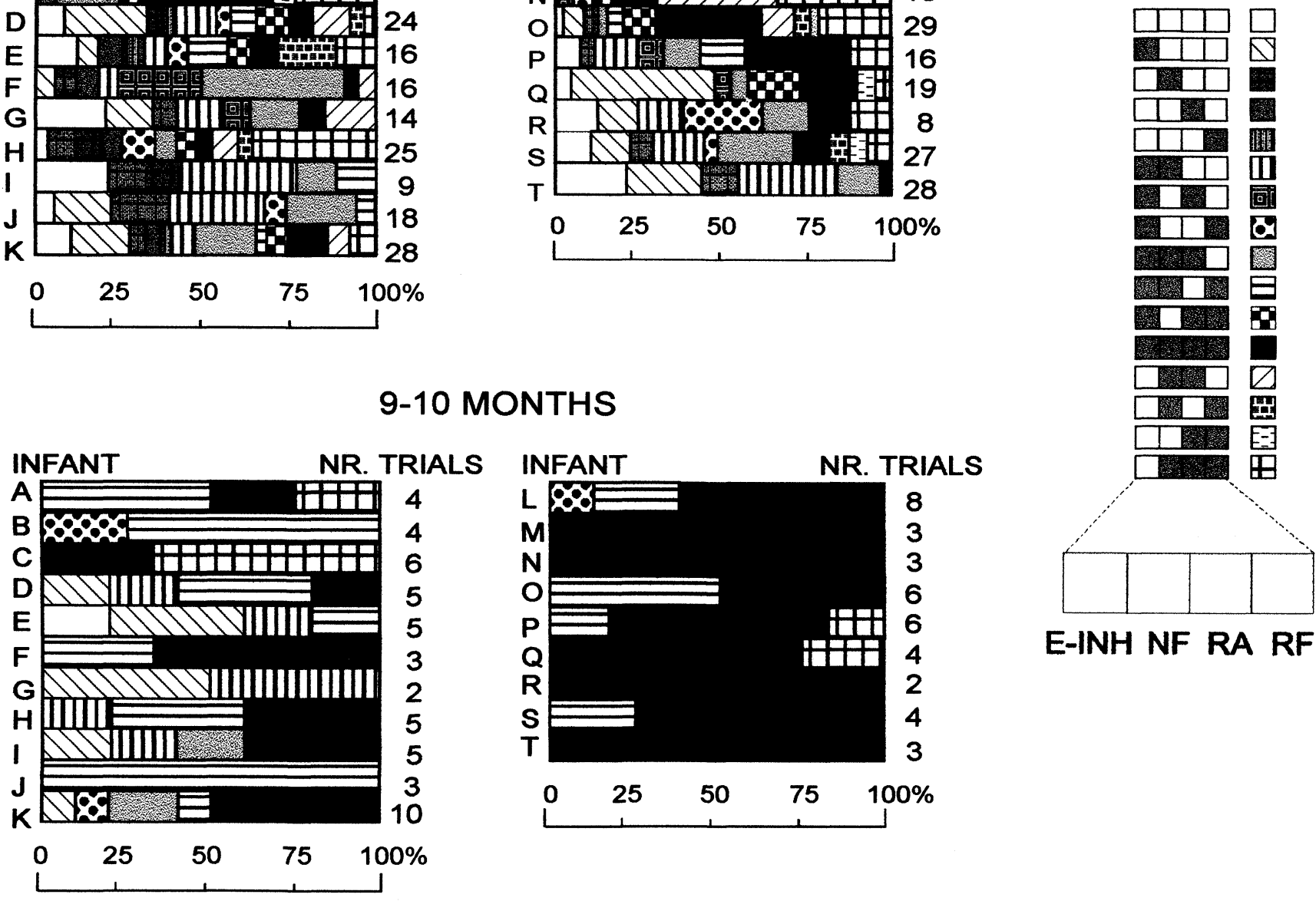

Fig. 2: Developmental changes in postural adjustments during sitting in 20 healthy infants. The balancing abilities in nine infants was trained by their parents by presenting the infants attractive toys, sidewards, and semi-backwards in the borderzone of reaching without falling ('trained' group). Training was performed three times a day for five minutes for a period of three months after the first assessment of the postural adjustments. The postural adjustments were assessed at the ages of 5-6 and 9-10 months during slow translations of a moving platform which induced a backward sway of the body of the sitting infant. In each horizontal bar, the distribution of response patterns of the direction specific postural adjustments for one subject is represented. The diagram on the right supplies the hatching codes of the response patterns used in the left part of the figure. In this diagram the shading of the squares indicate: square number 1: inhibition of one or more extensor muscles, square number 2: activation of $\mathrm{NF}=$ neck flexor muscle, square number 3 : activation of $\mathrm{RA}=$ rectus abdominis muscle, square number 4: activation of RF = rectus femoris muscle. NF, RA and RF are the direction specific muscles activated to prevent a fall of the body in backward direction. Note the decrease in variation of response patterns with increasing age, a process which is significantly enhanced by daily balance training, and which results in selection of the pattern in which all direction specific muscles are activated. Adapted from Hadders-Algra et al. 1996b. 
1999a). The other two factors, the site of the lesion and the timing of the insult, are interdependent. Lesions acquired prior to 36 weeks post-menstrual age (PMA) typically occur in the periventricular regions, whereas lesions acquired around term age in general are located in the cortical areas-with or without involvement of subcortical areas and/or the brain stem (Volpe, 1995). In preterm infants, it has been reported that frontally located lesions are associated with better outcomes than lesions located parietally or occipitally (Fawer et al., 1987; Fazzi et al., 1994).

Clinically, two groups of motor disorders are attributed to a lesion of the brain at early age: cerebraEDl palsy and clumsiness. Cerebral palsy (CP) is an umbrella term covering a group of nonprogressive, but often changing, motor-impairment syndromes secondary to lesions or anomalies of the brain arising in the early stages of development (Mutch et al., 1992). This means that CP-by definition-is caused by damage of the brain at early age, even though the abnormalities of the brain cannot always be visualized with imaging techniques. CP affects about 1 in 500 live born children (Hagberg et al., 1996). Clumsy children nowadays are classified according to DSM-IV as Developmental Coordination Disorder (DCD), a term in general denoting children who have such a poor motor coordination that it affects daily activities at home and at school, notwithstanding the presence of a normal intelligence and the absence of evident neurological pathology (American Psychiatric Association, 1994). The prevalence of DCD is about $10 \%$ (6\% to $13 \%$; Hadders-Algra, in press). In children with $\mathrm{DCD}$, the connection between structural abnormalities of the brain and motor dysfunctions is rather ambiguous. Recently Hadders-Algra and Touwen (in press) argued that indications for pre- and perinatal brain damage can be found in only one-third of the children with minor motor dysfunctions. The motor disorder of the latter children could be regarded as a border- line form of cerebral palsy. The motor problems of the remaining majority of clumsy children might be based on dysfunctions at the microscopic level of the nervous system, such as abnormalities in the neurotransmitter or receptor systems (Hadders-Algra \& Groothuis, 1999; Hadders-Algra et al., 1999a; Van der Fits et al., 1999a).

\section{NGST and developmental motor disorders}

Extending NGST to the domain of abnormal motor development offers an interesting perspective for the sequelae of brain lesions. Following the lines of thought of NGST, it can be surmised that a lesion of the brain at early age results in (a) a loss or a reduction of neuronal repertoires and (b) impaired selection (Hadders-Algra, 2000b). Large lesions of the brain would induce a complete loss of primary neuronal repertoires, resulting in failure to develop specific functions. Recent data on the development of postural control support this suggestion. We found that children with severe spastic tetraplegia, who did not develop the ability to sit independently, did not possess the primary direction-specific repertoires of postural adjustments (Hadders-Algra et al., 1999a,b). Less extensive lesions would result in a reduction of the primary neuronal repertoires and a reduced variation in motor behavior (Fig. 3). Indeed, one of the major signs of infants with brain damage is stereotyped motility, which at early age is expressed in the form of stereotyped GMs. It has been well established that lesions of the brain, resulting in the development of $\mathrm{CP}$, induce GMs which are devoid of variation and complexity (HaddersAlgra et al., 1997; Prechtl et al., 1997; Fig. 3). The lack of variation can also be observed in the muscle coordination patterns of these abnormal GMs. The patterns either show a synchronous activation of all participating muscles or a stereotyped reciprocal activity (Hadders-Algra et al., 1997). 

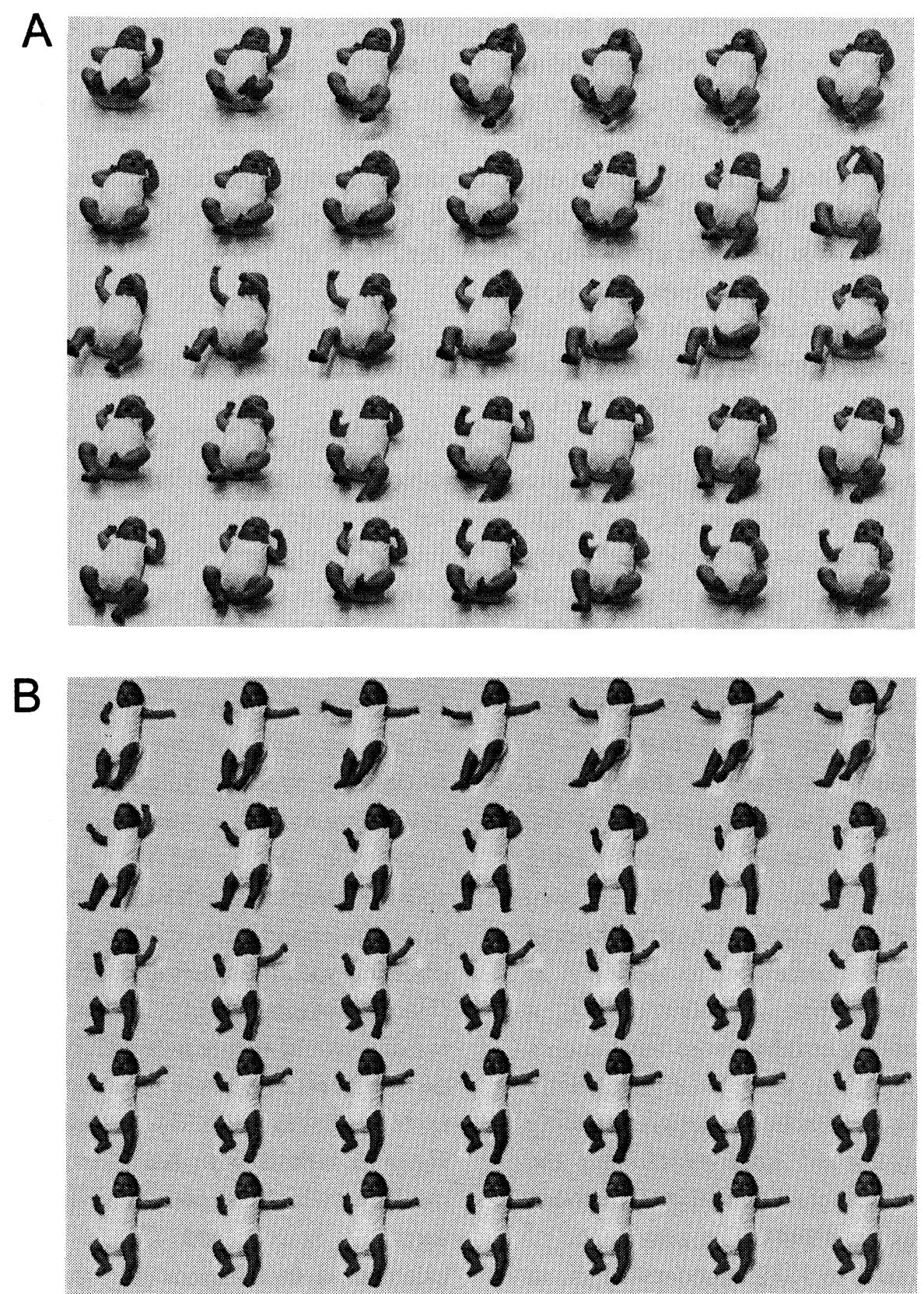

Fig. 3: Representation of videofragments of GMs of two infants aged 3 months post term. The fragments start at the upper left hand corner and should be read as the lines in a book. The interval between the frames is $8.16 \mathrm{~s}$. The infant in the upper panel (A) was born at term. She shows normal, variable, and complex GMs. The variation is illustrated by the different postures of the limbs in the different frames. Movement complexity is exemplified by the movement of the left leg on the third row: the movement is not a simple flexion-extension movement, but a flexion-extension combined with a simultaneous abduction at the hip and an endorotation of the foot. The infant in the lower panel (B) is born prematurely at a gestational age of 28 weeks. She has definitely abnormal GMs. The deviant character of the movements is expressed by the lack of variation: the frames have a high degree of similarity. The frames give the false impression that the infant did not move at all, but she moved equally much as infant $\mathrm{A}$. (Figure published with permission of the parents and the Nederlands Tijdschrift voor Geneeskunde where the figure was published originally [Hadders-Algra 1997, 141, p. 817]). 
It is common clinical knowledge that reduced variation continues to be the hallmark of motor behavior of infants with CP: they show little variation in spontaneous posture and motility and in various infantile reactions and responses (Ingram, 1966; Bobath, 1966; Touwen, 1978). Also at older age, the motor behavior of children with $\mathrm{CP}$ is characterized by stereotypy (Bobath, 1966; Aicardi \& Bax, 1998). For instance, the typical posture of the most affected arm in children with spastic hemiplegia is a posture with the shoulder in adduction, flexion, and endorotation, the elbow in flexion and pronation, and the wrist and fingers in (semi)flexion (Ingram, 1966). Recently, these clinical observations were confirmed in experimental studies. Studies, in which the postural abilities of children with borderline, mild, and moderate forms of $\mathrm{CP}$ were assessed with the help of perturbation experiments, revealed which the repertoire of directionspecific postural adjustments in these children was significantly reduced (Brogren et al., 1998; HaddersAlgra et al., 1999a). Likewise, a study on the spatial-temporal organization of spontaneous leg movements during the first half year of life demonstrated that the kicking movements of infants with $\mathrm{CP}$, due to lesions of the periventricular white matter, were characterized by reduced variation (Vaal et al., in press).

It is conceivable that children with borderline to moderate forms of $\mathrm{CP}$ not only suffer from a limited motor repertoire but also from deficiencies in the processes of selection. Selection can be hampered by impairments in the processing of proprioceptive, tactile, or visual information, dysfunctions which are frequently encountered in children with CP (Nashner et al., 1983; Yekutiel et al., 1994; Cioni et al., 1996). Recent data on the development of postural adjustments during reaching in infants with CP corroborate this suggestion. Healthy infants select the most efficient postural adjustments to compensate for the postural perturbation of a reaching movement between the ages of 12 and 18 months, whereas in children with $\mathrm{CP}$, moderate variation in postural adjustments during reaching persists beyond the age of 18 months. This suggests that the selection of the most efficient postural adjustment has not occurred by that age (Van der Fits et al., 1999c; Hadders-Algra et al., 1999b).

Presumably, children with borderline to moderate forms of $\mathrm{CP}$ do reach the phase of secondary variability, be it with some delay. It is likely that also at the level of the secondary repertoires, the impaired sensory processing interferes with the process of selection, i.e., the selection of the best motor solution for specific motor tasks. This would imply that children with borderline to moderate forms of CP have difficulties in adapting their motor behavior accurately to specific conditions because of the double problem of a hampered selection out of a limited repertoire (Fig. 4). Recent data confirm this suggestion. Children with mild to moderate forms of $\mathrm{CP}$ have problems in adjusting the forces of their fingers during object manipulation (Eliasson et al., 1992, 1995; Gordon \& Duff, 1999; Gordon et al., 1999; Eliasson \& Gordon, 2000). They also have difficulties in adapting their postural adjustments to specific conditions, such as the velocity of a reaching movement or the degree of pelvis-tilt while sitting (Hadders-Algra et al., 1999a,b). An inappropriate selection of the best motor solution induces variation in the fine-tuning of motor behavior: variations in the timing of motor events and in the scaling of the forces employed (Eliasson et al., 1992, 1995; Valvano \& Newell, 1998; Gordon \& Duff, 1999; Gordon et al., 1999; Eliasson \& Gordon, 2000). Recent studies support the idea that deficits in sensory processing contribute to the variation in the scaling of motor output of children with mild to moderate forms of CP. The studies showed that practice, implying repetition of self-generated sensory input (Valvano \& Newell, 1998; Gordon \& Duff, 1999; Gordon et al., 1999), and augmentation of 


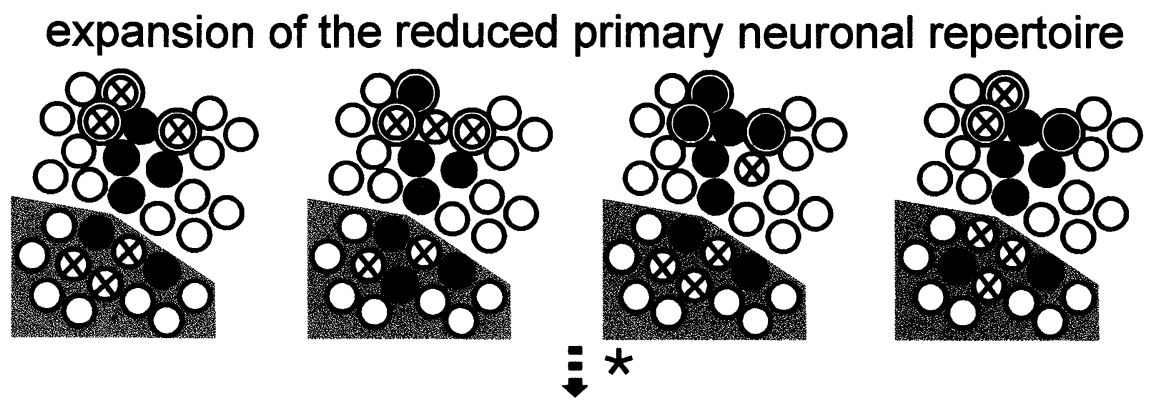

impaired selection

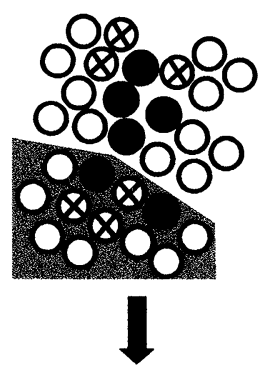

secondary neuronal repertoire

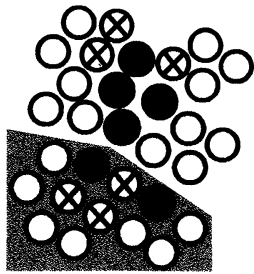

constraint a

E $*$

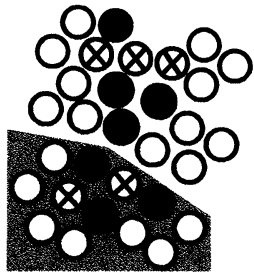

constraint b

E $t$

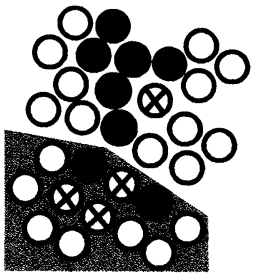

constraint c E

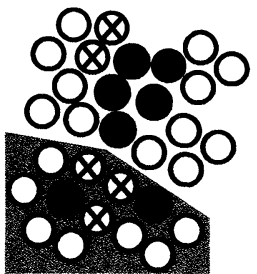

constraint d

E $*$

impaired selection impaired selection impaired selection impaired selection
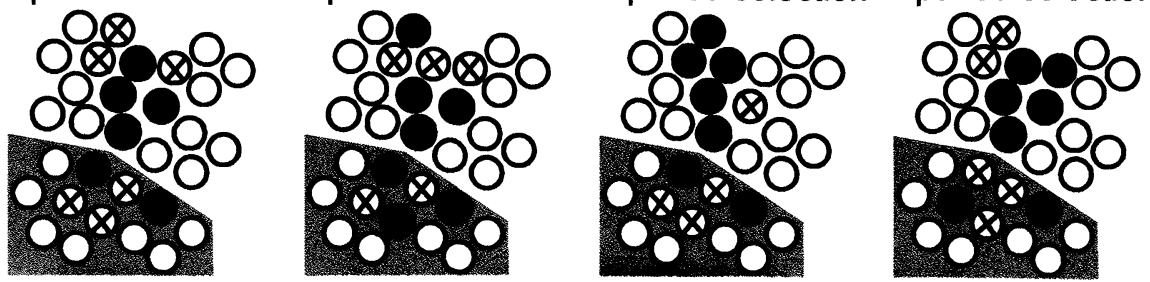

Fig. 4: Schematic diagram of the putative mechanisms of intervention after brain lesion at early age, based on the principles of NGST. The diagram is a twin partner of Fig. 1 (see legends of Fig. 1). The lower grey area denotes a lesion of the brain at early age. The lesion of the brain resulted in a reduction of the primary repertoire of the filled clusters; only four of the originally nine participating clusters were left (cf., Fig. 1). NGST suggests that at early age intervention should focus on augmentation of the primary repertoires. This is illustrated at the upper row of the diagram. Plastic changes induced a functional change of three neighboring clusters. This is indicated by the three clusters, which were non-filled in Fig. 1, but are depicted here with filled circles with double margins. Thus, the reorganization resulted in a restoration of a part of the lost variation. NGST suggests that at older ages, the focus of intervention should be on the provision of ample opportunities for active practice, as a richness in practice might form a compensation for the impaired selection processes (point of focus indicated by $(*)$ in the diagram). 
movement-related afferent information (HaddersAlgra et al., 1999b) result in a decrease of variation in motor output and thus in a better task-specific adaptation of motor behavior.

NGST offers especially a framework for the understanding of the so-called 'negative'" signs of $\mathrm{CP}$, i.e., the paresis and central dyscoordination. Most likely, these 'negative' movement disorders are more disabling for persons with $\mathrm{CP}$ than the 'positive' problems of $\mathrm{CP}$, such as spasticity, musculoskeletal malformations, dyskinesia, and persistent infantile reactions (Forssberg \& HaddersAlgra, in press; $c f$. ., Landau, 1974). Still, clinical care mainly focuses on the latter phenomena, with paresis and dyscoordination receiving relatively little attention. Of course, the treatment of 'positive' problems should not be discarded. But neurohabilitation of children with $\mathrm{CP}$ could gain substantially by including interventions which aim at a reduction of sensorimotor dyscoordination. In this respect, the framework of NGST could offer a helping hand.

\section{NGST: STRATEGIES FOR INTERVENTION AFTER A BRAIN LESION AT EARLY AGE}

Brain damage at early age is followed by considerable plastic changes. These changes, which are regarded as mediators of - at least a part of functional recovery, vary with the age of the insult and the size of the lesion (Kolb \& Whishaw, 1989; Kolb, 1995). For instance, plasticity and recovery are relatively large when the lesion is small and when the lesion occurs after the completion of neuronal migration during the period when the

\footnotetext{
${ }^{2}$ The neurologist Jackson divided neurological symptoms into two categories: negative ones, which denote a deficit of normal behavior due to destruction of neural tissue, and positive ones, which indicate exaggerated or distorted forms of behavior due to action of neurons released from their normal integrative relationship with other neural structures (Walshe, 1961).
}

processes of dendritic outgrowth and synapse formation are highly active (Kolb, 1995; Villablance \& Hovda, 2000). The latter means that in the human, considerable plasticity can be expected when lesions occur between 2 and 3 months before and 6 and 8 months after term age. In general, plasticity does not involve the generation of new neurons, but a change in functional destination of existing neurons (Kolb, 1995; Kujala et al., 2000). An exception to this general rule is the recent finding that midline frontal cortex lesions in neonatal rats can be followed by the regeneration of cortical tissue, the degree of regeneration being related to the degree of functional recovery (Kolb et al., 1998). But usually, plasticity implies a reprogramming of spared neural tissue, i.e., a reorganization of the remaining cortical-subcortical networks and their descending projections (Carr et al., 1993; Cao et al., 1994; Chu et al., 2000). In terms of NGST, plasticity could mean that the neurons neighboring a lesioned-and thus reducedprimary neuronal repertoire change function and get incorporated into the affected repertoire (Fig. 4). This results in a recovery of the lesioned function in the form of a less reduced primary repertoire. Yet, the price of this reorganization can be a moderate reduction of multiple primary neuronal repertoires, including those not directly affected by the lesion. A price, which clinically can be expressed by multiple dysfunctions and an overall drop in IQ (Vargha-Khadem et al., 1992; Kolb, 1995).

Notwithstanding the possible costs of reorganization, the net results of plastic changes occurring after a lesion of the brain at early age are usually positive. From the NGST point of view, this could mean that early intervention after brain lesion should attempt to increase the primary repertoires. Presumably this could be achieved by providing the infant with variable experiences. Variation in motor experience could, for instance, be obtained by varying the infant's posture, as posture is the basis for motility (Massion, 1998). The 
question whether or not an increase in primary variability can be achieved is a subject for future research. At present, the body of literature on intervention in young infants has neglected the long-term effect of intervention on motor development. But in analogy to the beneficial effects of the early stimulation of cognitive development in infants biologically at risk because of preterm birth (Infant Health and Development Program, 1990), it can be hypothesized that well-defined early sensorimotor intervention might have a similar positive effect on motor development.

In addition to the focus on variable experiences in order to increase the primary repertoires, NGST suggests which intervention at early age should aim at facilitating selection. Studies on normal motor development indicated that frequent experience with trial and error enhances the process of selection (Hadders-Algra et al., 1996b; Vereijken \& Thelen; 1997). Other studies on motor development in healthy infants showed that the effect of training is specific and does not generalize to other motor functions (Super, 1976; Zelazo et al., 1993). Possibly, training is most effective when the infant indicates that a specific motor skill is in developmental focus (McGraw, 1935; Super, 1976). It can be surmised that the process of selection in infants with deficits in the processing of sensory information on the basis of a brain lesion requires considerably more repetition of trial and error experiences than the selection in typically developing infants does. In other words, infants with neurological dysfunction might benefit from ample opportunities to actively try developing motor skills.

In older children with borderline to moderate forms of $\mathrm{CP}$, dysfunctions in the secondary variability are most prominent. NGST suggests that children with these types of dysfunctions will benefit from active practice, which will enhance the processes of selection and thereby the production of better adapted motor behavior. Indeed, experimental studies which evaluated the effect of training on specific motor skills in children with $\mathrm{CP}$ indicated that active experience improves motor function (Valvano \& Newell, 1998; Gordon \& Duff, 1999; Gordon et al., 1999). In clinical practice, children with $\mathrm{CP}$ are seldom treated according to standardized programs. For instance, the frequently used NeuroDevelopmental Treatment consists of a mixture of the application of handling techniques and an encouragement of active movement-with each therapist creating her/his own mixture of methods (DeGangi \& Royeen, 1994). The finding that the programs with the highest frequencies of treatment (5-7 times per week) have the best results supports the notion of NGST that ample practice can promote motor development in children with $\mathrm{CP}$ (Bower \& McLellan, 1992; Bower et al., 1996).

\section{CONCLUDING REMARKS}

From the point of view of NGST, intervention therapies for children with motor dysfunctions at early age should focus on provision of variable sensorimotor experiences. The latter might be achieved by means of the application of variable postures which counteract the infant's propensity to produce stereotyped activity. With increasing age, the emphasis of intervention shifts to the provision of ample opportunities for active practice, as plentiful practice might form a compensation for the impaired selection. In children with spastic hemiplegia, the technique of prolonged restraint of the relatively unaffected arm might be helpful. This technique, which successfully has been applied in subjects with chronic motor impairment after stroke, induces a forced use of the affected arm by blocking the use of the unaffected arm (Wolf et al., 1989; Taub et al., 1993). In addition, it is important to realize that children with brain dysfunction need more practice than their non-affected peers. Therefore, it is essential to reinforce the child's motivation by creating an ecological, playful 
setting with positive feedback (Harter, 1978; Graves, 1995; Sims et al., 1996).

\section{ACKNOWLEDGEMENTS}

I thank Eva Brogren and Tineke Dirks for their critical and valuable remarks on a previous draft of this manuscript. Jolanda Schaap is gratefully acknowledged for technical assistance in the preparation of the figures.

\section{REFERENCES}

Adolph KE, Vereijken B, Denny MA. 1998. Learning to crawl. Child Dev 69: 1299-1312.

Aicardi J, Bax M. 1998. Cerebral palsy. In: Aicardi J, ed, Diseases of the Nervous System in Childhood, $2^{\text {nd }}$ edition. Clinics in Developmental Medicine No. 115/118, Cambridge, UK: Mac Keith Press; 210-239.

American Psychiatric Association. 1994. Diagnostic and Statistical Manual of Mental Disorders, $4^{\text {th }}$ edition. Washington, DC, USA: American Psychiatric Association; 358.

Bobath K. 1966. The motor deficit in patients with cerebral palsy. Clinics in Developmental Medicine No. 23. London, UK: William Heinemann Med Books; 54.

Bower E, McLellan DL. 1992. Effect of increased exposure to physiotherapy on skill acquisition of children with cerebral palsy. Dev Med Child Neurol 34: 25-39.

Bower E, McLellan DL, Arney J, Campbell MJ. 1996. A randomized controlled trial of different intensities of physiotherapy and different goals setting procedures in 44 children with cerebral palsy. Dev Med Child Neurol 38: 226-237.

Bressler SL. 1995. Large scale cortical networks and cognition. Brain Res Rev 20: 288-304.

Brogren E, Hadders-Algra M, Forssberg H. 1998. Postural control in sitting children with spastic diplegia. Neurosci Biobehav Rev 22: 591-596.

Burnett CN, Johnson EW. 1971. Development of gait in childhood: Part II. Dev Med Child Neurol 13: 207-215.
Cao Y, Vikingstad EM, Huttenlocher PR, Towle Vl, Levin DL. 1994. Functional magnetic resonance studies of the reorganization of the human hand sensorimotor area after unilateral brain injury in the perinatal period. Proc Nat Acad Sci USA 91: 9612-9616.

Carr LJ, Harrison LM, Evans AL, Stephens JA. 1993. Patterns of central motor reorganization in hemiplegic cerebral palsy. Brain 116: 1223-1247.

Changeux J-P. 1997. Variation and selection in neural function. Trends Neurosci 20: 291-293.

Changeux J-P, Danchin A. 1976. Selective stabilisation of developing synapses as a mechanism for the specification of neuronal networks. Nature 264: 705-712.

Chu D, Huttenlocher PR, Levin DN, Towle VL. 2000. Reorganization of the hand somatosensory cortex following perinatal unilateral brain injury. Neuropediatrics 31: 63-69.

Cioni G, Duchini F, Milianti B, Paolicelli PB, Sicola E, Boldrini A, et al. 1993. Differences and variations in the patterns of early independent walking. Early Hum Dev 35: 193-205.

Cioni G, Fazzi B, Ipata AE, Canapicchi R, Van HofVan Duin J. 1996. Correlation between cerebral visual impairment and magnetic resonance imaging in children with neonatal encephalopathy. Dev Med Child Neurol 38: 120-132.

Costello AM deL, Hamilton PA, Baudin J, Townsend J, Bradford BC, Stewart AL, et al. 1988. Prediction of neurodevelopmental impairment at four years from brain ultrasound appearance of very preterm infants. Dev Med Child Neurol 30: 711-722.

DeGangi GA, Royeen CB. 1994. Current practice among NeuroDevelopmental Treatment Association members. Am J Occup Therapy 48: 803809.

De Vries JIP, Visser GHA, Prechtl HFR. 1982. The emergence of fetal behavior. I. Qualitative aspects. Early Hum Dev 7: 301-322.

Diener HC, Bootz F, Dichgans J, Bruzek W. 1983. Variability of postural reflexes in humans. Exp Brain Res 52: 423-428.

Edelman GM. 1989. Neural Darwinism. The Theory of Neuronal Group Selection. Oxford, UK: Oxford University Press; 371.

Edelman GM. 1993. Neural Darwinism: Selection and reentrant signaling in higher brain function. Neuron 10: 115-125. 
Edelman GM, Tononi G. 2000. Consciousness: How Matter Becomes Imagination. London, UK: Allen Lane, The Penguin Press; 274.

Eliasson AC, Gordon AM. 2000. Impaired force coordination during object release in children with hemiplegic cerebral palsy. Dev Med Child Neurol 42: 228-234.

Eliasson AC, Gordon AM, Forssberg H. 1992. Impaired anticipatory control of isometric forces during grasping by children with cerebral palsy. Dev Med Child Neurol 34: 216-225.

Eliasson AC, Gordon AM, Forssberg H. 1995. Tactile control of isometric finger forces during grasping in children with cerebral palsy. Dev Med Child Neurol 37: 72-84.

Evans GA. 1998. The human genome project. Arch Neurol 55: 1287-1290.

Fallang B, Saugstad OD, Hadders-Algra M. 2000. Goal directed reaching and postural control in supine position in healthy infants. Behav Brain Res 115: 9-18.

Fawer CL, Diebold P, Calame A. 1987. Periventricular leucomalacia and neurodevelopmental outcome in preterm infants. Arch Dis Childhood 62: 30-36.

Fazzi E, Orcesi S, Caffi L, Ometto A, Rondini G, Telesca C, et al. 1994. Neurodevelopmental outcome at 5-7 years in preterm infants with periventricular leukomalacia. Neuropediatrics 25: 134-136.

Ford LM, Steichen J, Steichen PA, Babcock D, Fogelson MH. 1989. Neurologic status and intracranial hemorrhage in very-low-birthweight preterm infants. Outcome at 1 year and 5 years. Am J Dis Children 143: 1186-1190.

Forssberg H. 1985. Ontogeny of human locomotor control. I. Infant stepping, supported locomotion and transition to independent locomotion. Exp Brain Res 57: 480-493.

Forssberg H, Hadders-Algra M. In press. Pathophysiology of movement disorders in cerebral palsy. In: Velcikovic Perat M, Neville B, eds, Cerebral Palsy. Amsterdam, the Netherlands: Elsevier Science Publ.

Forssberg H, Hirschfeld H. 1994. Postural adjustments in sitting humans following external perturbations: Muscle activity and kinematics. Exp Brain Res 97: 515-527.

Forssberg H, Eliasson A-C, Redon-Zouitenn C, Mercuri E, Dubowitz L. 1999a. Impaired grip-lift synergy in children with unilateral brain lesions. Brain 122: 1157-1168.
Forssberg H, Juaite A, Hadders-Algra M. 1999b. Shared memory representations for programming of lifting movements and associated whole body postural adjustments. Neurosci Lett 273: 9-12.

Gesell A, Amatruda CS. 1947. Developmental diagnosis. Normal and Abnormal Child Development, $2^{\text {nd }}$ edition. New York, NY, USA: Harper \& Row; 496.

Gordon AM, Charles J, Duff SV. 1999. Fingertip forces during object manipulation in children with hemiplegic cerebral palsy. II. Bilateral coordination. Dev Med Child Neurol 41: 176-185.

Gordon AM, Duff SV. 1999. Fingertip forces during object manipulation in children with hemiplegic cerebral palsy. I. Anticipatory scaling. Dev Med Child Neurol 41: 166-175.

Graves P. 1995. Therapy methods for cerebral palsy. J Paediatric Child Health 31: 24-28.

Greenough WT, Black JE, Wallace CS. 1987. Experience and brain development. Child Dev 58: 539-559.

Grillner S, Deliagina T, Ekeberg Ö, El Manira A, Hill RH, Lansner A, et al. 1995. Neural networks which coordinate locomotion and body orientation in lamprey. Trends Neurosci 18: 270-279.

Hadders-Algra M. 2000a. The Neuronal Group Selection Theory: An attractive framework to explain variation in normal motor development. Dev Med Child Neurol 42: 566-572.

Hadders-Algra M. 2000b. The Neuronal Group Selection Theory: promising principles for the understanding and treatment of motor disorders. Dev Med Child Neurol 42: 707-715.

Hadders-Algra M. In press. The clumsy child-at the border of cerebral palsy? In: Velcikovic Perat M, Neville B, eds, Cerebral Palsy. Amsterdam, The Netherlands: Elsevier Science Publ.

Hadders-Algra M, Brogren E, Forssberg H. 1996a. Ontogeny of postural adjustments during sitting in infancy: Variation, selection and modulation. $\mathrm{J}$ Physiol 493: 273-288.

Hadders-Algra M, Brogren E, Forssberg H. 1996b. Training affects the development of postural adjustments in sitting infants. J Physiol 493: 289 298.

Hadders-Algra M, Brogren E, Forssberg H. 1998. Postural adjustments during sitting at pre-school age: The presence of a transient toddling phase. Dev Med Child Neurol 40: 436-447.

Hadders-Algra M, Brogren E, Katz-Salamon M, Forssberg H. 1999a. Periventricular leukomalacia 
and preterm birth have a different detrimental effect on postural adjustments. Brain 122: 727-740.

Hadders-Algra M, Dirks T. 2000. De motorische ontwikkeling van de zuigeling: variëren, selecteren en leren adapteren. Houten: Bohn, Stafleu \& Van Loghum; 117.

Hadders-Algra M, Groothuis AMC. 1999. Quality of general movements in infancy is related to the development of neurological dysfunction, attention deficit hyperactivity disorder and aggressive behavior. Dev Med Child Neurol 41: 381-391.

Hadders-Algra M, Klip-Van den Nieuwendijk AWJ, Martijn A, Van Eykern LA. 1997. Assessment of general movements: Towards a better understanding of a sensitive method to evaluate brain function in young infants. Dev Med Child Neurol 39: 88-98.

Hadders-Algra M, Touwen BCL. In press. Perinatal events and soft neurological signs in neurobehavioral outcome studies. Dev Neuropsychol.

Hadders-Algra M, Van der Fits IBM, Stremmelaar EF, Touwen BCL. 1999b. Development of postural adjustments during reaching in infants with cerebral palsy. Dev Med Child Neurol 41: 766-776.

Hadders-Algra M, Van Eykern LA, Klip-van den Nieuwendijk AWJ, Prechtl HFR. 1992. Developmental course of general movements in early infancy. II. EMG correlates. Early Hum Dev 28: 231-252.

Hagberg B, Hagberg G, Olow I, Von Wendt L. 1996. The changing panorama of cerebral palsy in Sweden. VII. Prevalence and origin in the birth year period 1987-1990. Acta Paediatrica 85: 954-60.

Harter S. 1978. Effectance motivation reconsidered. Toward a developmental model. Hum Dev 21: 34-64.

Hebb DO. 1949. The organization of behavior. New York, NY, USA: Wiley; 303.

Hikosaka O, Nakahara H, Rand MK, Sakai K, Lu X, Nakamura K, et al. 1999. Parallel neural networks for learning sequential procedures. Trends Neurosci 22: 464-471.

Hirschfeld H, Forssberg, H. 1994. Epigenetic development of postural responses for sitting during infancy. Exp Brain Res 97: 528-540.

Huttenlocher PR, DeCourten C, Garey LJ, Van der Loos H. 1982. Synaptogenesis in human visual cortex - evidence for synapse elimination during normal development. Neurosci Lett 33: 247-252.
Infant Health \& Development Program. 1990. Enhancing the outcomes of low-birth-weight, premature infants. J Am Med Assoc 263: 3035-3042.

Ingram TTS. 1966. The neurology of cerebral palsy. Arch Dis Childhood 41: 337-357.

Jernigan TL, Trauner DA, Hesselink JR, Talla PA. 1991. Maturation of the human cerebrum observed 'in vivo' during adolescence. Brain 114: 2037-2049.

Kolb B. 1995. Brain Plasticity and Behavior. Mahwah, New Jersey, USA: Lawrence Erlbaum Assoc.; 183.

Kolb B, Gibb R, Gorny G, Whishaw IQ. 1998. Possible regeneration of rat medial frontal cortex following neonatal frontal lesions. Behav Brain Res 91: 127-141.

Kolb B, Whishaw IQ. 1989. Plasticity in the neocortex: Mechanisms underlying recovery from early brain damage. Prog Neurobiol 32: 235-276.

Konczak J, Borutta M, Topka H, Dichgans J. 1995. The development of goal-directed reaching in infants: Hand trajectory formation and joint torque control. Exp Brain Res 106: 156-168.

Konishi Y, Takaya R, Kimura K, Konishi K, Fujii Y, Saito M, et al. 1994. Development of posture in prone and supine position during the preterm period in low risk preterm infants. Arch Dis Childhood 70: F188-F191.

Kujala T, Alho K, Näătänen R. 2000. Cross-modal reorganization of human cortical functions. Trends Neurosci 23: 115-120.

Landau WM. 1974. Spasticity: The fable of a neurological demon and the emperor's new therapy. Arch Neurol 31: 217-219.

Largo RH, Molinari L, Weber M, Comenale Pinto L, Duc G. 1985. Early development of locomotion: Significance of prematurity, cerebral palsy and sex. Dev Med Child Neurol 27: 183-191.

Liu Y, Gao J-H, Liotti M, Pu Y, Fox PT. 1999. Temporal dissociation of parallel processing in the human subcortical outputs. Nature 400: 364-367.

Magnus R, De Kleijn A. 1912. Die abhängigkeit des Tonus der Extremitätenmuskeln von der Kopfstellung. Pflüger's Archiv 145: 455-548.

Massion J. 1998. Postural control systems in developmental perspective. Neurosci Biobehav Rev 22: 465-472.

McGraw M. 1935. Growth: A study of Johnny and Jimmy. New York, NY, USA: Appleton-Century; 316. 
McGraw MB. 1943. The neuromuscular maturation of the human infant. (reprinted in: Classics in Developmental Medicine, no. 4, London, UK: Mac Keith Press, 1989; 117).

Minkowski M. 1938. Neurobiologische Studien am menschlichen Foetus. In: Abderhalden E, ed, Handbuch der biologischen Arbeitsmethoden. Abt. V: Methoden zum Studium der Funktionen der einzelne Organe im Tierischen Organismus. Teil 5B. Berlin, Germany: Urban \& Schwarzenberg; 511-619.

Müller K, Ebner B, Hömberg V. 1994. Maturation of fastest afferent and efferent central and peripheral pathways: No evidence for a constancy of central conduction delay. Neurosci Lett 166: 9-12.

Mutch L, Alberman E, Hagberg B, Kodama K, Velickovic Perat M. 1992. Cerebral palsy epidemiology: Where are we now and where are we going? Dev Med Child Neurol 34: 547-555.

Nashner LM, Shumway-Cook A, Marin O. 1983. Stance posture control in a select group of children with cerebral palsy: Deficits in sensory organization and muscular coordination. Exp Brain Res 49: 393-409.

Nelson PG, Fields RD, Yu C, Liu Y. 1993. Synapse elimination from the mouse neuromuscular junction in vitro: A non-Hebbian activity dependent process. $\mathrm{J}$ Neurobiol 24: 1517-1530.

O'Leary DDM. 1989. Do cortical areas emerge from a protocortex? Trends Neurosci 12: 400-406.

Peiper A. 1963. Cerebral function in infancy and childhood, $3^{\text {rd }}$ edition. New York, NY, USA: Consultants Bureau; 683.

Prechtl HFR. 1990. Qualitative changes of spontaneous movements in fetus and preterm infant are a marker of neurological dysfunction. Early Human Dev 23: 151-158.

Prechtl HFR, Einspieler C, Cioni G, Bos A, Ferrari F, Sontheimer D. 1997. An early marker of developing neurological handicap after perinatal brain lesions. The Lancet 339: 1361-1363.

Prechtl HFR, Nolte R. 1984. Motor behavior of preterm infants. In: Prechtl HFR, ed, Continuity of Neural Functions From Prenatal to Postnatal Life. Clinics in Developmental Medicine No. 94, Oxford, UK: Blackwell Scientific Publications; 79-92.

Purves D. 1994. Neural activity and the growth of the brain. Cambridge, UK: Cambridge University Press; 106.
Rakic P. 1988. Specification of cerebral cortical areas. Science 241: 170-176.

Rakic P, Bourgeois JP, Eckenhoff MF, Zecevic N, Goldman-Rakic PS. 1986. Concurrent overproduction of synapses in diverse regions of the primate cerebral cortex. Science 232: 232-235.

Schomburg ED. 1990. Spinal sensorimotor systems and their supraspinal control. Neurosci Res 7: 265-340.

Sherrington CS. 1906. The physiological position and dominance of the brain. In: Sherrington CS, ed, The Integrative Action of the Nervous System. London, UK: Constable \& Comp.; 308-353.

Sims K, Henderson SE, Morton J, Hulme C. 1996. The remediation of clumsiness. II Is kinaesthesis the answer? Dev Med Child Neurol 38: 988-997.

Simmers J, Meyran P, Moulins M. 1995. Modulation and dynamic specification of motor rhythmgenerating circuits in crustacea. J Physiol (Paris) 89: 195-208.

Sporns O, Edelman GM. 1993. Solving Bernstein's problem: A proposal for the development of coordinated movement by selection. Child Dev 64: 960-981.

Statham L, Murray MP. 1971. Early walking patterns of normal children. Clin Orthopedics Related Res 79: 8-24.

Super CM. 1976: Environmental effects on motor development: The case of 'African Infant Precocity'. Dev Med Child Neurol 18: 561-567.

Taub E, Miller N, Novack TA, Cook III EW, Fleming WC, Nepomuceno CS, et al. 1993. Technique to improve chronic motor deficit after stroke. Arch Phys Med Rehab 74: 347-354.

Thelen E. 1985. Developmental origins of motor coordination: Leg movements in human infants. Dev Psychobiol 18: 1-22.

Thelen E. 1995. Motor development. A new synthesis. Am Psychologist 50: 79-95.

Thelen E, Corbetta D, Kamm K, Spencer JP, Schneider K, Zernicke RF. 1993. The transition to reaching: Mapping intention and intrinsic dynamics. Child Dev 64: 1058-1098.

Touwen BCL. 1975. Variability and stereotypy in normal and deviant development. In: Apley J, ed, Care of the Handicapped Child. Clinics Dev Med No. 67, London, UK: Heinemann Medical Books; 99-110.

Touwen BCL. 1993. How normal is variable, or how variable is normal? Early Human Dev 34: 1-12. 
Ulrich BD. 1997. Dynamic systems theory and skill development in infants and children. In: Connolly $\mathrm{KJ}$, Forssberg $\mathrm{H}$, eds, Neurophysiology and Neuropsychology of Motor Development. Clinics in Developmental Medicine No. 143-144, London, UK: Mac Keith Press; 319-345.

Vaal J, Van Soest AJ, Hopkins B, Sie LTL, Van der Knaap MS. 2000. Development of spontaneous leg movements in infants with and without periventricular leukomalacia. Exp Brain Res 135: 94-105.

Valvano J, Newell KM. 1998. Practice of a precision isometric grip-force task by children with spastic cerebral palsy. Dev Med Child Neurol 40: 464 473.

Vargha-Khadem F, Isaacs E, Van der Werf S, Robb S, Wilson J. 1992. Development of intelligence and memory in children with hemiplegic cerebral palsy. Brain 115: 315-329.

Van der Fits IBM, Klip AWJ, Van Eykern LA, Hadders-Algra M. 1998. Postural adjustments accompanying fast pointing movements in standing, sitting and lying adults. Exp Brain Res 120: 202216.

Van der Fits IBM, Flikweert ER, Stremmelaar EF, Martijn A, Hadders-Algra M. 1999a. Development of postural adjustments during reaching in preterm infants. Pediatr Res 46: 1-7.

Van der Fits IBM, Klip AWJ, Van Eykern LA, Hadders-Algra M. 1999b. Postural adjustments during spontaneous and goal-directed arm movements in the first half year of life. Behav Brain Res 106, 75-90.

Van der Fits IBM, Otten E, Klip AWJ, Van Eykern LA, Hadders-Algra M. 1999c. The development of postural adjustments during reaching in 6 to 18 months old infants: Evidence for two transitions. Exp Brain Res 126: 517-528.

Vereijken B, Thelen E. 1997. Training infant treadmill stepping: The role of individual pattern stability. Dev Psychobiol 30: 89-102.

Verhage M, Maia AS, Plomp JJ, Brussaard AB, Heeroma JH, Vermeer H, et al. 2000. Synaptic assembly of the brain in the absence of neurotransmitter secretion. Science 287: 864-868.

Villablance JR, Hovda DA. 2000. Developmental neuroplasticity in a model of cerebral hemispherectomy and stroke. Neuroscience 95: 625-637.

Vles JSH, Kingma H, Caberg H, Daniels H, Casaer P. 1989. Posture of low-risk preterm infants between 32 and 36 weeks postmenstrual age. Dev Med Child Neurol 31: 191-195.

Volpe JJ. 1995. Neurology of the Newborn, $3^{\text {rd }}$ edition. Philadelphia, Pennsylvania, USA: Saunders; 876.

Von Hofsten C. 1991. Structuring of early reaching movements: A longitudinal study. J Motor Behav 23: 280-292.

Walshe FMR. 1961. Contributions of John Huglings Jackson to neurology: A brief introduction to his teachings. Arch Neurol 5: 119-131.

Wolf SL, Lecraw DE, Barton LA, Jann BB. 1989. Forced use of hemiplegic upper extremities to reverse the effect of learned nonuse among chronic stroke and head-injured patients. Exp Neurol 104: 125-132.

Yekutiel M, Jariwalda M, Stretch P. 1994. Sensory deficit in the hands of children with cerebral palsy: A new look at assessment and prevalence. Dev Med Child Neurol 36: 619-624.

Zelazo NA, Zelazo PR, Cohen KM, Zelazo PD. 1993. Specificity of practice effects on elementary neuromotor patterns. Dev Psychobiol 29: 686-691. 

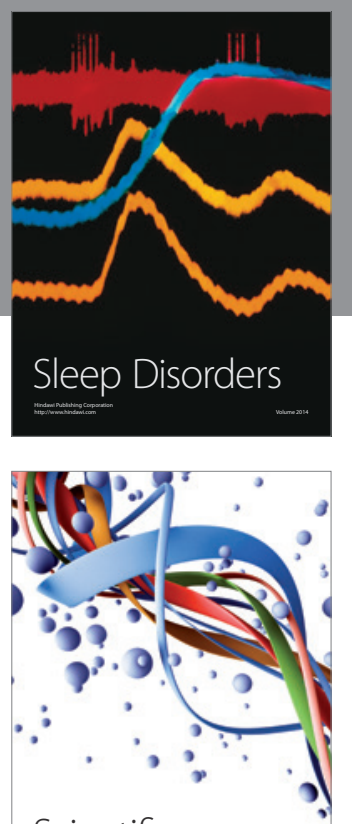

Scientifica
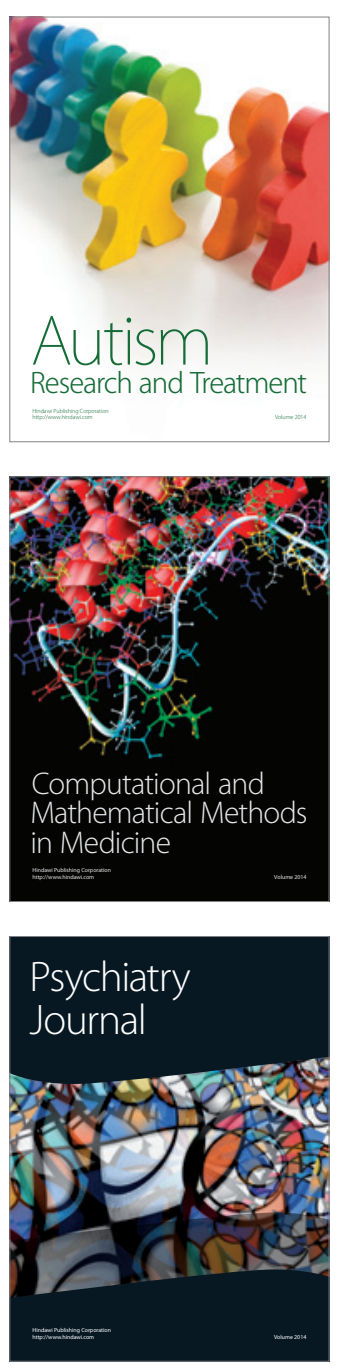
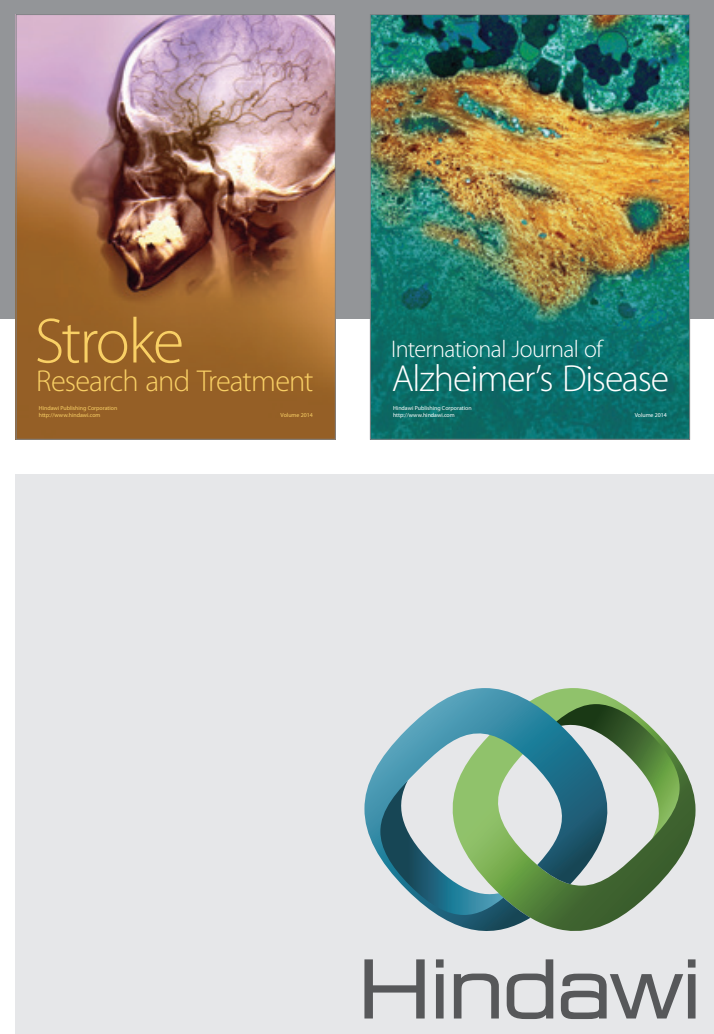

Submit your manuscripts at

http://www.hindawi.com
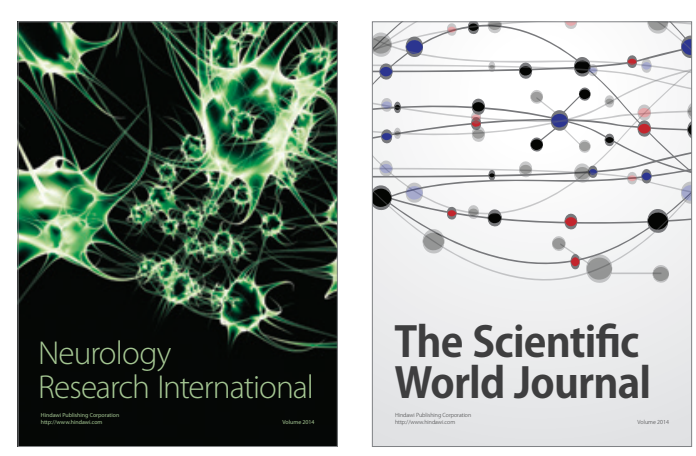

The Scientific World Journal

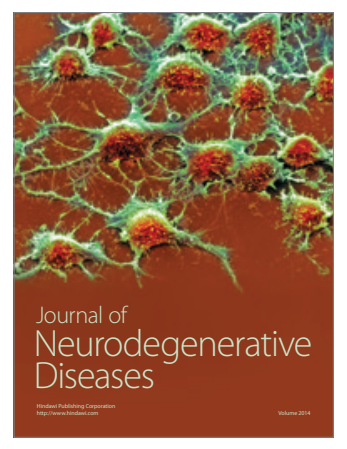

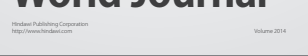

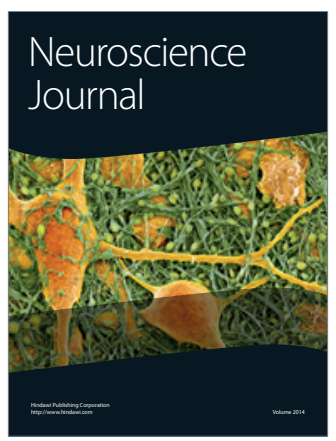

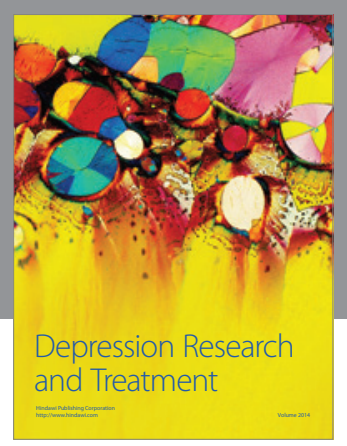
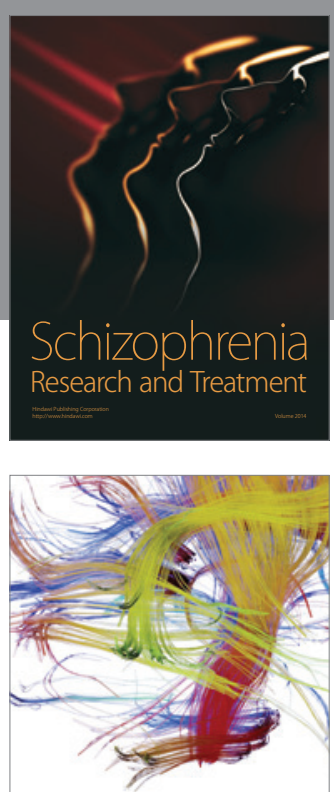

Brain Science

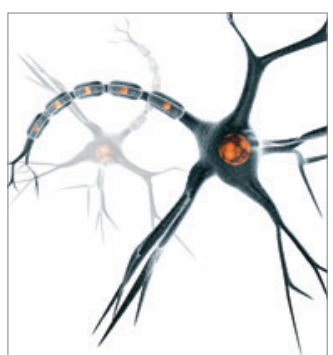

Neural Plasticity
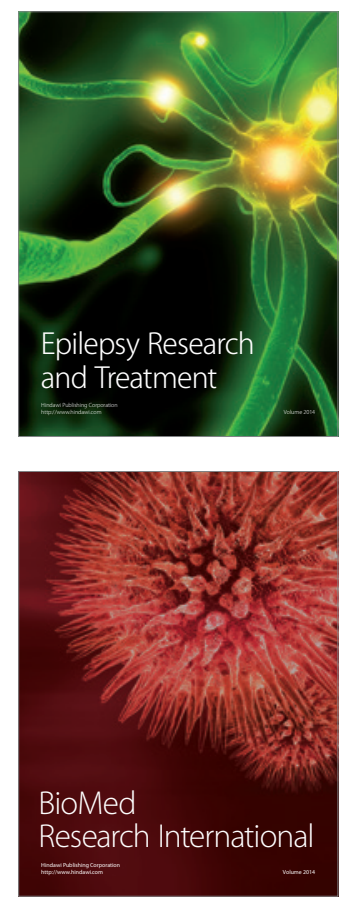

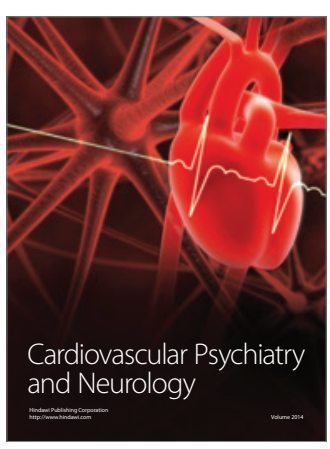

Parkinson's

Disease
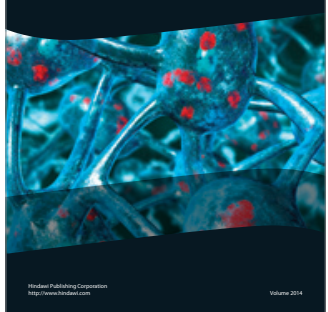